\title{
Design and Analysis of Bi-planar Antenna for Long Term Evolution Base Stations
}

\author{
Prof. Muhamad Angriawan \\ Department of Computer Engineering, IRC Russia \\ muhamadaggriawan@mail.ru
}

\begin{tabular}{|c|c|}
\hline Article History & Abstract \\
\hline $\begin{array}{l}\text { Article Submission } \\
21 \text { February } 2018 \\
\text { Revised Submission } \\
15 \text { April } 2018 \\
\text { Article Accepted } \\
19 \text { May } 2018 \\
\text { Article Published } \\
30 \text { June } 2018\end{array}$ & $\begin{array}{l}\text { In this article, A bi-planar receiving antenna is planned for LTE convenient base } \\
\text { stations. The proposed reception apparatus involves two parts one for the upper band } \\
\text { and another for lower band. It can in like manner be shown without granulating } \\
\text { folds. The lower band has the pair of printed dipoles with two or three parasitic parts } \\
\text { for transmission limit improvement. The upper band contains a few crumbled dipoles. } \\
\text { The microstrip line and dipole are cut on a comparative substrate. The upper bana } \\
\text { segments are wrapped in lower band segments encircling a diminished structure. The } \\
\text { bi-planar receiving wire achieves an information transmission of around } 2 \mathrm{GHz} \text {. The } \\
\text { arranged receiving wire can be completed in versatile base stations. The radio wire } \\
\text { increase achieved around } \sim 12 \text { dbi which is sensible for the adaptable } \\
\text { correspondence base station structures. } \\
\text { Keywords: Bi-Planar antenna, dipoles, Parasitic elements, Base stations }\end{array}$ \\
\hline
\end{tabular}

\section{Introduction}

The improvement of versatile frameworks requires broadband and minimal effort reduced radio wire structure. The different portable correspondence frameworks have been assigned with various recurrence bands. The $2 \mathrm{G}$ frameworks and the future LTE (4G) frameworks will work in the $2.3 \mathrm{GHz}(2300-2400 \mathrm{MHz})$ and $2.6 \mathrm{GHz}$ (2570-2690 MHz) groups. Henceforth base station receiving wires can at the same time spread different isolated recurrence groups focused at $900 \mathrm{MHz}$ and $2.2 \mathrm{GHz}$ that are essential for current correspondence frameworks that can give $4 \mathrm{G}$ multifunctional administrations [1][2].

The extremely fast changes in technical requirements and strong demands in the application market the latest advances in antenna technologies for a variety of base stations in mobile wireless communication systems has been a challenge in radio frequency industry. A base station antenna is a complex device that must provide highly reliable service over a period of many years. The dual broadband planar antenna is used for the mobile communications such as $2 \mathrm{G} / 3 \mathrm{G} / \mathrm{LTE}$ applications. In these systems, antennas play a vital role as one of the key components or subsystems. The rapid proposal of new applications has also spurred strong demands for new high-performance antennas. Although the fundamental physical principles of antennas have not changed, designing the antenna have been experiencing the rapid advancement of antenna technologies [3].

The design has been implemented using the Agilent ADS.As for as bandwidth enhancement, impedance coordinating system, thick substrate, capacitive remuneration, different patches or gap coupling procedure. Diminishing receiving wire tallness offers ascend to a lessening in data transmission and this impact is free of the innovation utilized. In fact, the limited transfer speed normal for microstrip receiving wires can't meet the consistently expanding transmission capacity request of most current multiband frameworks. Along these lines, it is exceptionally attractive to create double broadband planar reception devices [4].

In the current systems, the reception apparatus is comprises of a couple of collapsed dipoles that are coupled and taken care of by a L-moulded micro strip line. The broadband radio wire has the planar arrangement for data 
transfer capacity improvement. The arrival misfortune RL $>15 \mathrm{~dB}$, transmission capacity is $53 \%$ and the reception apparatus gain is around $9 \mathrm{dBi}$. The dipoles are combined with a L-molded line. The dipole structure of receiving wire is scratched on a similar substrate. These radio antennas can understand confinement of $30 \mathrm{~dB}$ by utilizing two components which are opposite to one another. The tallness $(\mathrm{H})$ of the radio wire component over the reflector affects the impedance coordinating of the broadband reception apparatus element [5].

The high-gain and broadband small elements array for a slot loop antenna is used. The antenna can cover LTE bands at the expense of small size. Gain is $\sim 12 \mathrm{dbi} \& \sim 14 \mathrm{dbi}$ for lower $\&$ upper bands. Frameworks like LTE are multiband frameworks using assortment of recurrence groups builds the limit and permit expansion of numerous functionalities. Considering multiband frameworks, a receiving wire is unquestionably one of the key gadgets since it is good with numerous recurrence groups [6].

\section{Related Works}

Few methods have been reported to broaden the bandwidth, by utilizing two circular elements such as a wideband planar dipole antenna with parasitic patches which exhibit acceptable radiation pattern with a broaden impedance. Furthermore, to combat the narrowband according to Yagi antenna, a novel high-gain and broadband small elements array for a slot loop antenna is investigated. The antenna can cover LTE's bands at the expense of smaller size [7]. The radio wire has a stacked geometry with a littler fix situated over the enormous one. For wide-band execution each fix is energized by an autonomous L-formed test. Another element is included this plan is the lower fix is bolstered by four shorting wires. In doing as such, the taking care of test for energizing the upper L-test can experience problems without influencing the presentation of the bigger fix which is liable for emanating the lower frequencies.

In impedance coordinating system, capacitive remuneration, various patches and opening coupling method is utilized for data transmission upgrade [8]. Different twofold broadband accepting wires for base stations is used .In this paper, twofold broadband gathering mechanical assembly for $4 \mathrm{G}$ base station based applications. The proposed twofold broadband radio wire involves two or three dipoles for the lower band the upper band, moulding a twofold band gathering contraption unit. Along these lines, the twofold band accepting wire unit can be exhibited in the E-plane without the nearness of granulating projections [9].

The structure of gathering devices involving two strip dipoles, the arms of which are engraved dielectric substrate and related through an equivalent strip line is used. The accepting wires are expected to have far reaching band or twofold band limit sensible for application in remote correspondence systems. A critical good situation of these antennas is its fundamental structure with sophisticated circuits. Extensive band gathering mechanical assemblies with move speeds more noticeable than $30 \%$ for VSWR under 1.5 working near $2.0 \mathrm{GHz}$ and twofold repeat getting wires working at $1.5 \mathrm{GHz}$ and $1.8 \mathrm{GHz}$ gatherings. This paper concentrates on contraptions featuring wide band or twofold band movement where built up ease and low amassing cost are held.

The radio antennas contain standard course of action dealt with assortments of two strip dipoles recognized in twofold sided arrangement. Two assessment procedures are applied to structure these radio wires. One is a fullwave philosophy used for examination of strip dipoles engraved on a grounded dielectric substrate. In the other strategy, the printed strip channels are changed to indirect transports secured with dielectric or appealing spreads subject to the standard of semi static vitality [10].

The feed mastermind is also sorted out to such an extent, that the $1800-\mathrm{MHz}$ signal into the transmitting patch for the 900-MHzband activity (the rectangular-ring patch) is blocked, so is the condition for the $900 \mathrm{MHz}$ signal into the oozing patch for the $1800 \mathrm{MHz}$ band development (the indented rectangular fix). In this condition, the conceivable excitation of deplorable modes can be secured and fundamental impedance arranging in both of the $900 \mathrm{MHz}$ and $1800 \mathrm{MHz}$ packs is accomplished [6]. 


\section{Proposed Methodology}

The bi-planar antenna consists of upper and lower bands. The lower band consists of printed dipoles and folded dipoles. The folded dipole structure influences impedance matching. The parasitic elements are used for bandwidth enhancement. The block diagram is shown in figure 1.

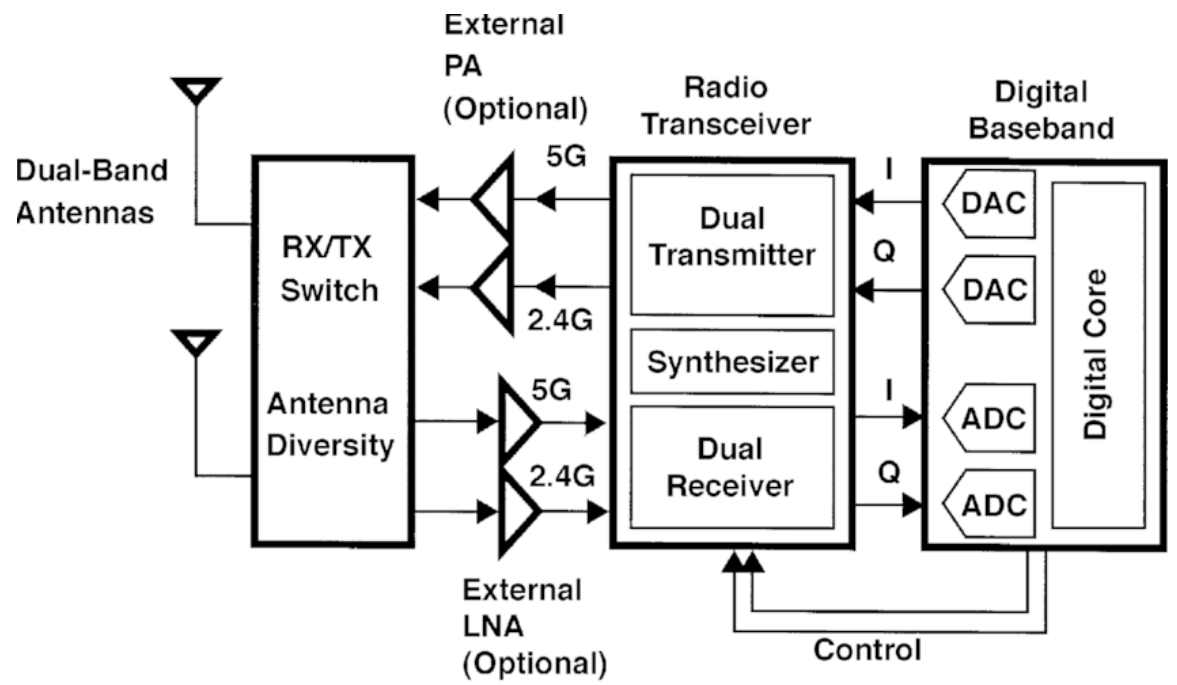

Fig 1: Basic block diagram of bi-planar antenna unit

The two dipoles of each section are connected through a coplanar strip line and are coupling managed by a miniaturized scale strip line. The twofold band getting wire parts are engraved on a FR4 substrate with a dielectric consistent of 4.4 , a difficulty deviation of 0.018 , and a thickness of $0.76 \mathrm{~mm}$. The height of the radio wire is $45 \mathrm{~mm}$. The size of the substrate is $360 \times 280 \mathrm{~mm}$. The length of the littler scope strip line and the width of the opening of the coplanar strip line can be balanced so commendable impedance arranging can be developed. The tolerant wire unit is put over a reflector for unidirectional radiation.

The significant immense parameter that impacts the getting wire execution is L1.Since there are three social event contraption parts in a twofold broadband radio wire unit, i.e., port 1 for the lower-band fragment, ports 2 and 3 for two upper-band sections. The most essential parameter for data transmission update at the lower band is $\mathrm{L} 1$ which is the length of the parasitic parts. By altering L1, a broadband presentation at the lower and can be developed and the structure is showed up in figure 2.

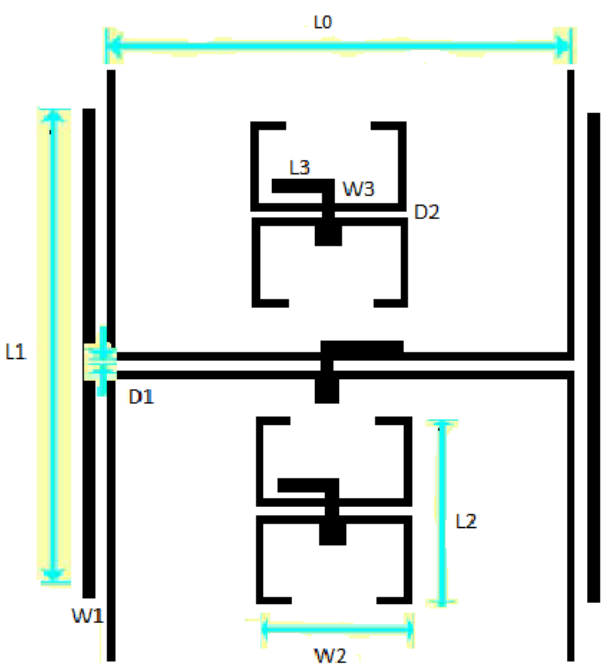

Fig 2: Basic structure of bi-planar antenna unit 
On the off chance that L1 expands, the extra reverberation draws nearer to the first resonance. The appropriate mix of extra and unique reverberation prompts better data transfer capacity enhancement. The second parameter that influences the impedance matching is L0.the separation between two dipoles of the lower-band element. It influences the extent of S11.

\section{Simulation Results}

The main objective to design a dual-band planar antenna and it should be capable of serving $2 \mathrm{G} / 3 \mathrm{G} / \mathrm{LTE}$ mobile base stations. The layout design obtained from ADS tool is shown in figure 3.

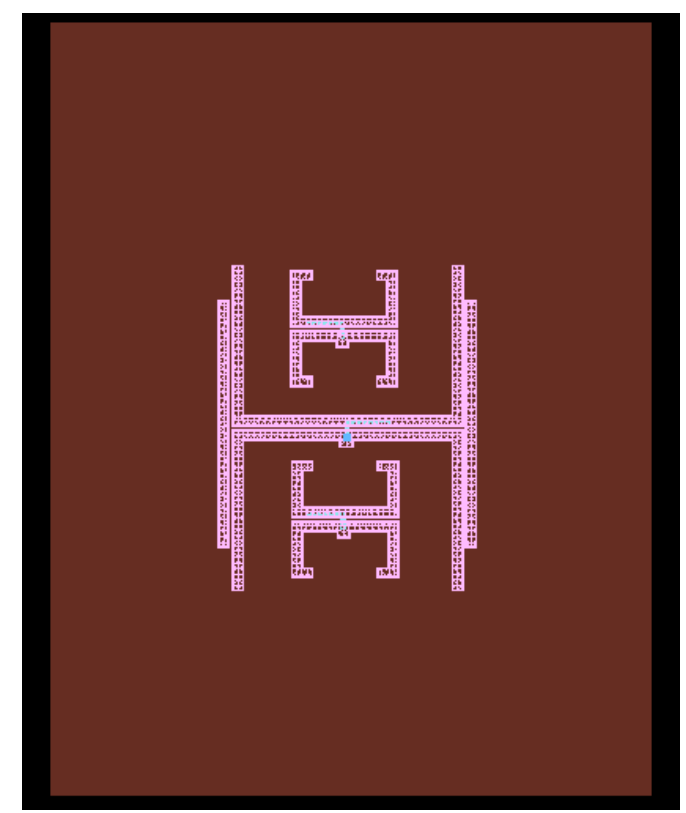

Fig 3 : Layout design of bi-planar antenna

Figure 3 depicts the dual broadband antenna unit .This structure consists of two upper bands and two lower bands. The upper bands consist of a pair of printed dipoles folded dipoles. The parasitic elements are used for bandwidth enhancement. Since the planar antenna is integrated with the coplanar waveguide the port 2 and 3 is given as ground with the port 1.It will be treated as a coplanar waveguide.

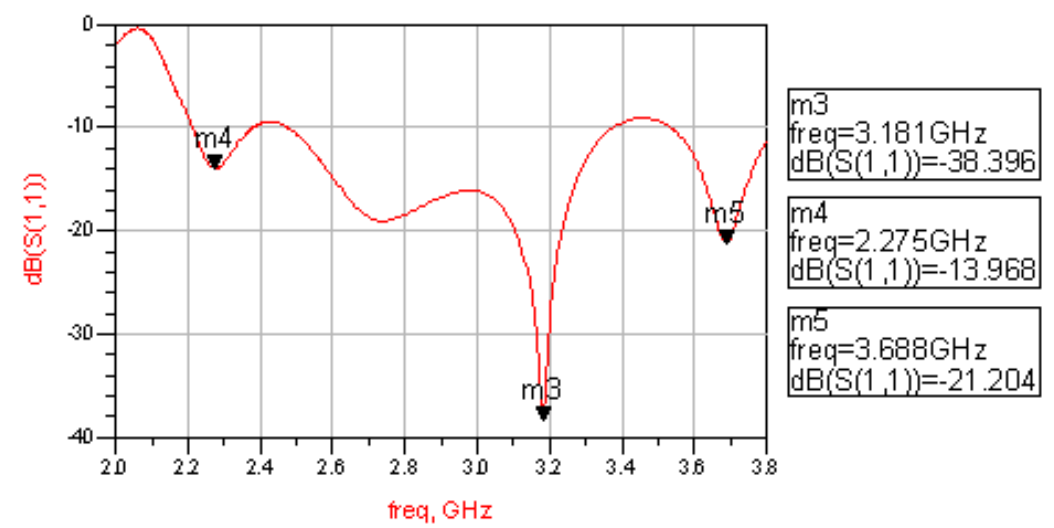

Fig 4: Performance of the bi-planar antenna 
Figure 4 depicts the performance of the broadband planar antenna base stations. The practical $4 \mathrm{G}$ systems can cover from 2-8 GHz. Within that frequency range itself the $3 \mathrm{G}$ frequency band is covered. Hence a single antenna system supports multiple wireless standards. The theoretical bandwidth is $5 \mathrm{GHz}$. But the practical bandwidth achieved here is $2 \mathrm{GHz}$.

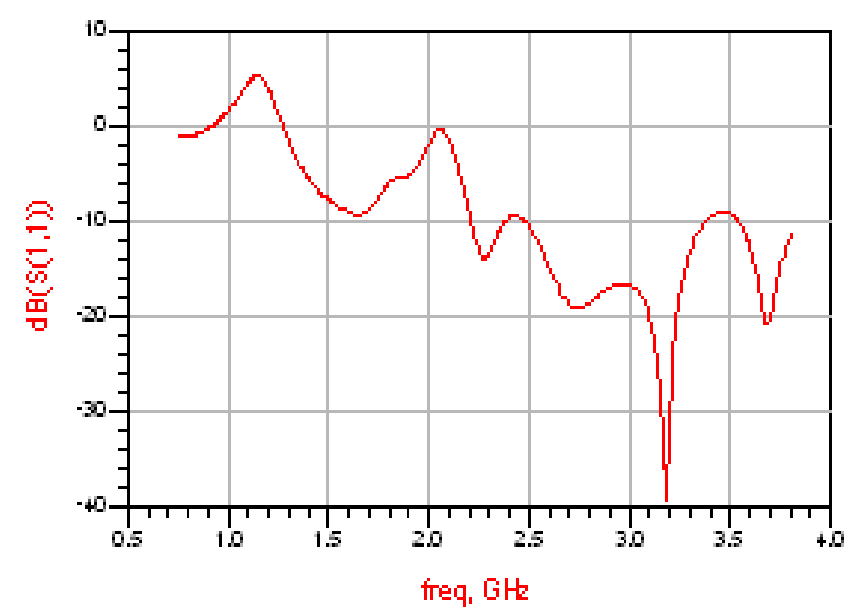

Fig 5: frequency curve for the bi-planar antenna

Figure 5 depicts the one port output for the designed planar broadband antenna.The bandwidth achieved here is around $1.8 \mathrm{GHz}$. It has the better gain performance than the three port system. The bandwidth can be enhanced by varying the micro strip slot. The pair of parasitic components is added to the lower band component to improve the transmission capacity of the lower band. The transmission capacity improvement of the upper band is because of the coupling feed and the reflector.

Figure 6 depicts the radiation pattern of proposed antenna. The radiation pattern obtained is the figure of eight pattern. This designed antenna is mainly used for base station antennas. This antenna is a reconfigurable one. For the upcoming radio wireless technologies this antenna can be supported. A single base station antenna serves for $2 \mathrm{G} / 3 \mathrm{G} / 4 \mathrm{G}$ handsets with compact size, bandwidth enhancement and impedance matching.

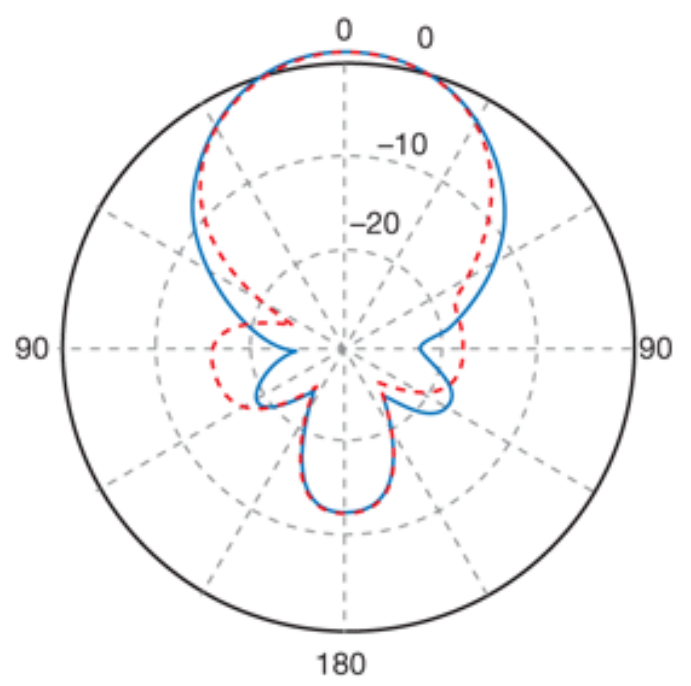

Fig 6: Radiation pattern for the bi-planar antenna 
TABLE IV PERFORMANCE OF VARIOUS ANTENNAS

\begin{tabular}{|c|c|c|c|c|}
\hline Parameters & $\begin{array}{c}\text { Frequency } \\
(\mathbf{G H z})\end{array}$ & Bandwidth(GHz) & Gain (dBi) & $\begin{array}{c}\text { Beam width } \\
\text { (degrees) }\end{array}$ \\
\hline Monopole antenna & 59 & 2.61 & 9.3 & 45 \\
\hline dipole antenna & 63.5 & 2.1 & 10.1 & 30 \\
\hline Single plane antenna & 74 & 3.4 & 14.6 & 60 \\
\hline Yagi antenna & 82 & 4.2 & 10.2 & 120 \\
\hline Dual band antennas & 86 & 5.4 & 12.6 & 45 \\
\hline Loop antenna & 94 & 6.2 & 10.4 & 120 \\
\hline bowtie & 88 & 4.9 & 8.6 & 45 \\
\hline Micro strip antennas & 74 & 8.2 & 12.4 & 30 \\
\hline Horn antenna & 86 & 6.4 & 11.4 & 60 \\
\hline Proposed antenna & 52 & 3.8 & 14.6 & 45 \\
\hline
\end{tabular}

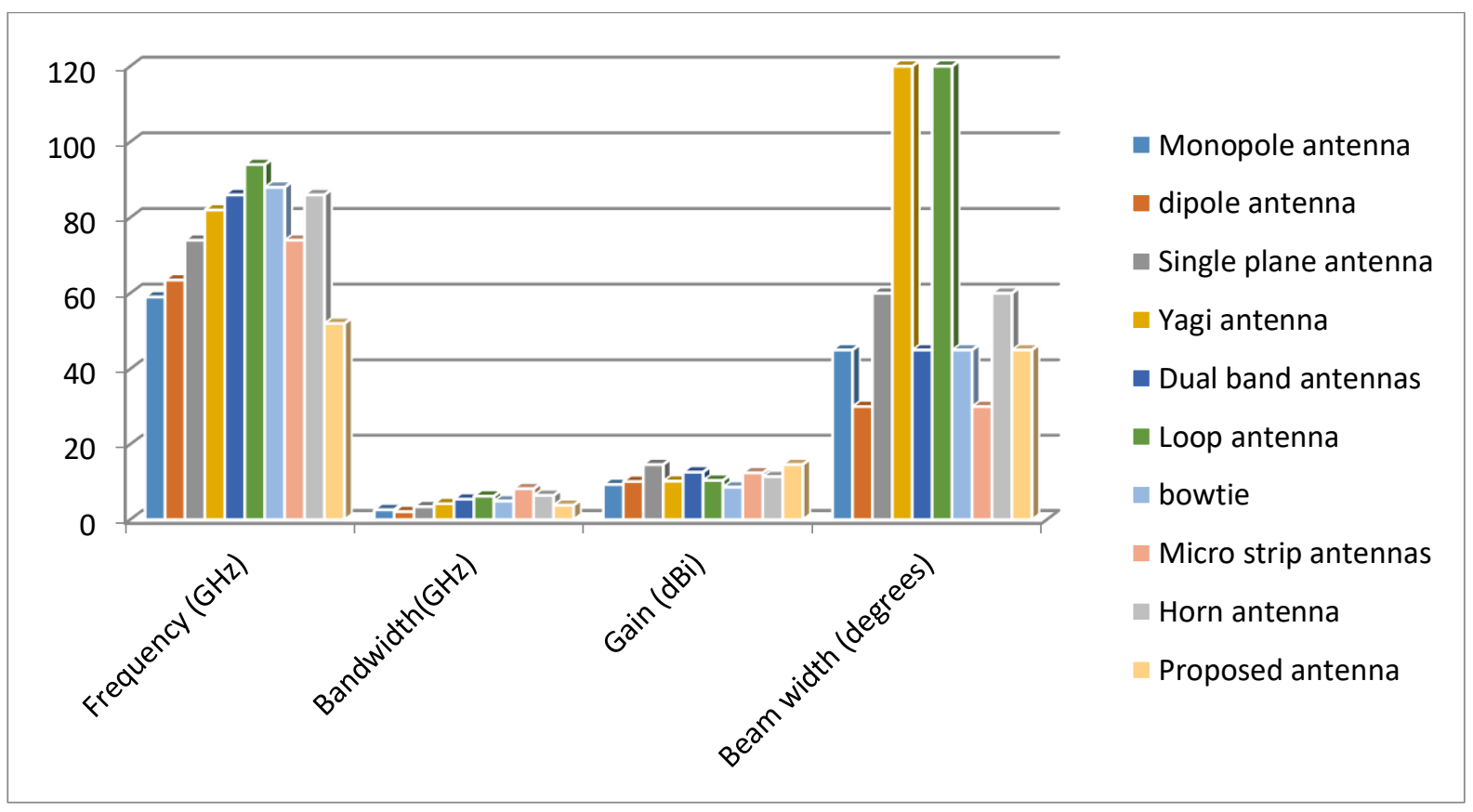

Fig 7: Comparison of various antenna parameters

\section{Conclusion}

The bi-planar has been designed and simulated using Agilent ADS tool. The performance of the antenna is found to be good in the case of $3 \mathrm{G} / 4 \mathrm{G}$ base station antennas. The bandwidth achievement is the important factor in the antenna design. This antenna provides better coverage capability than the conventional planar configuration antenna. The planar antenna is used for base stations because it provides better bandwidth enhancement, impedance matching and effective gain of the antenna. The structure of the antenna is compact so as to be mounted on the tower of the base station. This proposed antenna can be extended as future work by enhancing the $2 \mathrm{G}$ frequency and also as the dual broadband planar antenna as array of antennas for bandwidth enhancement and impedance matching. 


\section{References}

[1] YueHui Cui, RongLin Li, Senior Member, IEEE, and Peng Wang,"A Novel Broadband Planar Antenna for $2 \mathrm{G} / 3 \mathrm{G} / \mathrm{LTE}$ Base Stations", IEEE transactions on antennas and propagation, vol. 61, no. 5, may 2013.

[2] K. Wang and W. Lu, "Conceptual design of planar end fire circularly polarized antenna with enhanced directivity," 2017 Sixth Asia-Pacific Conference on Antennas and Propagation (APCAP), Xi'an, 2017, pp. 1-3, doi: 10.1109/APCAP.2017.8420337.

[3] M. Madani Fadoul, T. A. Rahman, and A. Moradikordalivand," Novel Planar Antenna for Long Term Evolution (LTE)", International Journal of Information and Electronics Engineering, Vol. 4, No. 1, January 2014.

[4] J. Yan, H. Wang, J. Yin, C. Yu and W. Hong, "Planar series-fed antenna array for $77 \mathrm{GHz}$ automotive radar," 2017 Sixth Asia-Pacific Conference on Antennas and Propagation (APCAP), Xi'an, 2017, pp. 13, doi: 10.1109/APCAP.2017.8420639.

[5] P. Li, K. M. Luk, and K. L. Lau," A Dual-Feed Dual-Band L-Probe Patch Antenna", IEEE transactions on antennas and propagation, vol. 53, no. 7, july 2005.

[6] Jiafeng Zhou, Kevin A. Morris, and Michael J. Lancaster, Senior Member, IEEE'” General Design of Multiway Multisection Power Dividers by Interconnecting Two-Way Dividers", IEEE transactions on microwave theory and techniques, vol. 55, no. 10, october 2007.

[7] YueHui Cui, RongLin Li, Senior Member, IEEE, and Peng Wang" Novel Dual-Broadband Planar Antenna and Its Array for 2G/3G/LTE Base Stations", ieee transactions on antennas and propagation, vol. 61, no. 3, march 2013.

[8] Tzung-Wern Chiou and Kin-Lu Wong, Senior Member, IEEE,"A Compact Dual-Band Dual-Polarized Patch Antenna for 900/1800-MHz Cellular Systems", ieee transactions on antennas and propagation, vol. 51, no. 8, august 2003.

[9] A. Kiyani, R. M. Hashmi and K. P. Esselle, "Dense, planar arrays of compact Resonant Cavity Antennas," 2017 IEEE International Symposium on Antennas and Propagation \& USNC/URSI National Radio Science Meeting, San Diego, CA, 2017, pp. 1973-1974, DOI: 10.1109/APUSNCURSINRSM.2017.8073029.

[10] Faton Tefiku, Member, IEEE and Craig A. Grimes, Member, IEEE, "Design of Broad-Band and DualBand Antennas Comprised of Series-Fed Printed-Strip Dipole Pairs", IEEE transactions on antennas and propagation, vol. 48 , no. 8 